\title{
Strategic Stress Intervention In The Academic Environment
}

Frances B. Wood, (frances.wood@selu.edu), Southeastern Louisiana University Connie Budden, (cbudden@ selu.edu), Southeastern Louisiana University

\begin{abstract}
Adding activities to employee agendas without simultaneously decreasing other activities tends to increase stress. Stress is an ever-present problem in the work environment. The academic work environment is no different from that of industry, in that employees potentially face the draining and sometimes ravaging effects that stress can impose on the human condition. A study was conducted to determine whether certain teaming activities and social events would reduce stress among the faculty in an academic department at a university in the south. The desire to reduce stress among members of the department was a commendable goal. However, despite the best of intentions, stress levels rose.
\end{abstract}

\section{INTRODUCTION}

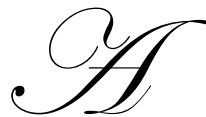

pproximately $40 \%$ of those who work outside the home report that their jobs are very or extremely stressful (Kelly, 2002). As described by Corey (1996), “Anxiety, arising from one's personal strivings to survive and to maintain and assert one's being, must be confronted as an inevitable part of the human condition;" therefore, stress is actually part of being human (Emerson, 2003). Managers nationwide are aware that occupational stress contributes to a significant portion of worker compensation claims, health-care costs, absenteeism, and productivity losses (Sauter, Murphy \& Hurrell, 1990). Employees also realize that this stress contributes to both personal and psychological problems.

The National Institute for Occupational Safety \& Health (NIOSH) created a model of job stress and health to help explain the complexities (Hurrell \& Murphy, 1995). The model, including both work and non-work variables, points to the intricacies of the issue of job-related stress. Osipow and Spokane (1987) also created a model incorporating both stressors and coping abilities. Figure 1 further explains stress by incorporating the model proposed by NIOSH and the variables from Osipow and Spokane (1987).

Managers and administrators nationwide continue to work to help employees avoid and manage stress. The earliest employee assistance programs (EAP's) were developed in the mid- 1920s during the Hawthorne Studies conducted by Western Electric (Dickson, 1945). During the 1940s and 1950s, occupational alcoholism programs emerged, as a way to treat "troubled" employees. By the 1990s, health promotion programs such as smoking cessation, weight reduction, and stress management began to surface. These programs reflect numerous changing strategies to increase employee productivity.

The high cost of stress exhibits itself psychologically (anxiety, depression, irritability), physiologically (hypertension, headaches, tension), and behaviorally (work performance, substance abuse). Understanding the causes of job stress by measuring it accurately and identifying problem areas, implementing interventions and re-evaluating the situation could prove useful (Murphy, 1995). 


\section{METHODOLOGY}

\section{Participants}

Eleven faculty members (ten females, one male, mean age $=42.3$ ) who predominately teach freshman and sophomore college students volunteered to participate in a project to reduce stress. The department had a major goal of reducing stress among the faculty while simultaneously increasing teamwork. Work environments where employees give much of themselves to their work, as caring professors often do in their efforts to reach and teach students, are ripe for stress-related dysfunctional impacts on the social fabric of individuals and the department in general.

\section{Instrumentation}

Historically, employee assistance programs have focused on characteristics of the employee, not characteristics of the job or organization, which might be causing employee stress (Murphy, 1995). As a result, the source of real stress problems in the workplace were not accurately diagnosed. Therefore, researchers in this study chose an instrument that would possibly reveal stressors in the environment, as well as those within the individual.

The faculty members of the test department completed the Occupational Stress Inventory (Osipow \& Spokane, 1987) prior to the beginning of efforts aimed at reducing stress. After completing the OSI, the administrators and faculty spent several months participating in a variety of interventions suggested by outside sources that were aimed at reducing stress among the members. Activities to reduce stress included regular meetings with the purpose of team building as well as a variety of social activities with the express purpose of encouraging social interaction among departmental members.

The pretest became the benchmark against which future measures would be compared to assess programmatic impacts. The $O S I$ is comprised of three major scales, each further defined by four to six sub-measures. Researchers hypothesized programmatic efforts to reduce stress in the department would create positive outcomes that could be generally assessed through the $O S I$ inventory posttest.

The first section of the OSI, the Occupational Roles Questionnaire (ORQ), uses six scales (or sub-measures) to assess occupational stress. This section measures: Role Overload, Role Insufficiency, Role Ambiguity, Role Boundary, Responsibility and Physical Environment. The ORQ basically measures the job stressors listed in the NIOSH model of job stress.

The second section of the OSI, referred to as the Personal Strain Questionnaire (PSQ), is composed of four scales that measure psychological strain within the test subject. The PSQ measure includes scales for Vocational Strain, Psychological Strain, Interpersonal Strain and Physical Strain. The PSQ corresponds to the individual and nonwork factors in Figure 1.

The third and final section of the OSI, Personal Resources Questionnaire (PRQ), measures coping resources of the individual. Some individual personalities, levels of self-esteem, and support systems influence the ability to cope. Like the PSQ, the PRQ is comprised of four scale factors measuring Recreation, Self-Care, Social Supports and a Rational/Cognitive measure. Finally, the PRQ measures the Buffer factors referred to in the NIOSH model (NIOSH 2004).

\section{Design And Procedure}

Faculty members were given the OSI pre-test near the end of the Fall 2002 Semester. The post-test was administered approximately four months later, in late April 2003. Eleven of the department's faculty participated in both the pre-test and post-test assessments. All three sections of the $O S I$ were completed. 
Data were recorded and analyzed using paired t-test in the Excel spreadsheet statistics function. The hypothesis that there would be no difference between the means of the measures in the pre-test and post-test governed the test. In other words, the null hypothesis expected that the difference between the means would be zero, indicating that the activities had no impact. Given a difference, it was hoped that the impact would be positive - that stress would be reduced.

\section{FINDINGS}

Results from the study indicate very little change in the faculty stress levels from the pre-test to the post-test. Despite much effort to reduce stress, stress levels did not decrease. A close look at the three individual major components that comprise the $O S I$ indicates that there were variations in the mean measures. These variations potentially are the result of the activities undertaken to reduce stress.

Table 1: Occupational Stress Inventory Pre- Post-Test Results

\begin{tabular}{|c|c|c|c|}
\hline Scale & Mean Pre-test & Mean Post-test & t-value \\
\hline Occupational roles & 17.46 & 18.39 & $2.30^{*}$ \\
\hline Personal Strain & 15.88 & 18.70 & $3.85^{* *}$ \\
\hline Personal Resource & 37.31 & 37.38 & 0.07 \\
\hline
\end{tabular}

$* p<.10 ; * * p<.05$

The Occupational Roles Questionnaire (ORQ) indicates an increase in the means from 17.47 to 18.39 . The positive increase in the difference between the means indicates a slight increase in occupational stress on the part of the faculty.

Despite a change in the means, and an increase at that, the means of the pre-test and post-test ORQ measure exhibited no statistically significant difference. As would be expected, the Pearson Correlation coefficient is very high, indicating that the measures are highly correlated. The .05 level of statistical significance was used to assess the variations in the mean measures; for further study, this was significant at the .10 level of statistical significance. Essentially, the activities undertaken did not change the stress levels related to occupational roles.

The Personal Strain Questionnaire (PSQ) measure also increased from 15.88 to 18.70. The difference in this sub-measure of $O S I$ that measures psychological strain indicates that a statistically significant difference did exist. The difference in the means does not equal zero. Apparently, the faculty experienced an increase in related stress as measured by psychological strain. This unexpected increase was statistically significant at greater than the .05 level.

The relatively low Pearson Correlation indicates little correlation between the measures. Such a low level of correlation is to be expected when there is a statistically significant difference in the measures.

The final measure, the Personal Resource Questionnaire (PRQ) indicates a slight increase in the coping resources of faculty during this period. The mean for the PRQ increased from 37.31 to 37.38 . This small increase is not statistically significant at the .05 level.

There were differences between the pre-test and post-test measures. It should be noted that all measures appeared to be within the normal range of scores for professionals taking this test as presented in Osipow and Spokane (1987).

An increase in the PRQ may be seen as a positive result of the teaming efforts and social activities in which the faculty participated as a part of this study. Thus, the impact of team development and social activities appears to have been a positive result of the effort. This positive result is encouraging although it is not statistically significant. 


\section{DISCUSSION}

The findings showed an increase in each measure. At all times, all measures were within the normal range of scores for professionals. However, only the psychological strain was found to have significantly increased from the fall to the spring at the .05 level. The increase in the PRQ (coping) measure is a positive increase but not significant enough of an increase to show measurable differences between the before and after scores. The findings indicate that teaming activities and social activities may have actually increased the stress and strain on faculty rather than reducing it. One limitation of this study is that the $O S I$ is normally reserved for individual analysis, rather than for a group as in this test. The small size of the study is also another limitation. Further research should be conducted with a larger sample to determine if these findings hold true for a larger faculty department.

Figure 1: Stress And The OSI

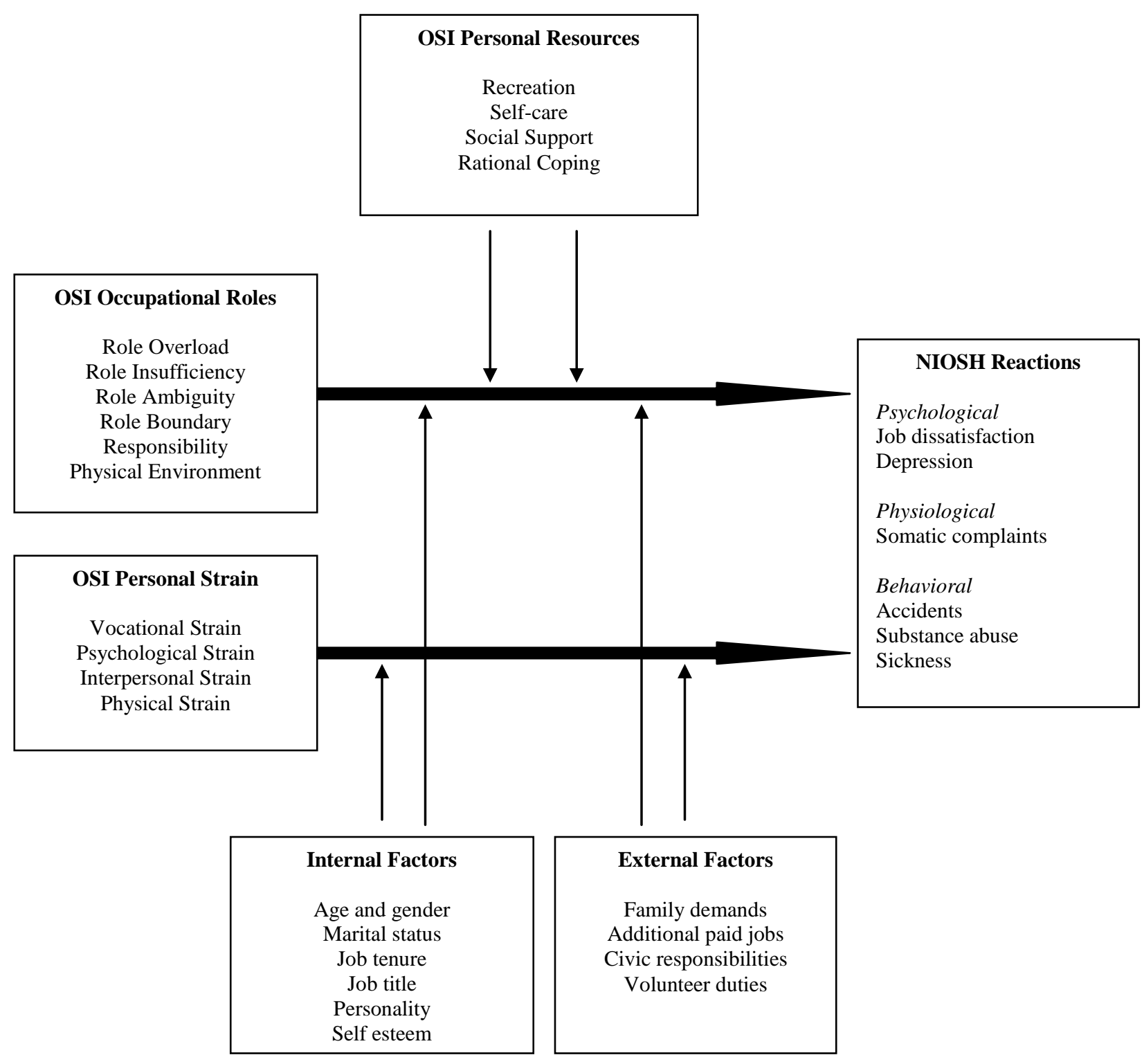




\section{REFERENCES}

1. Corey, G., (1996). Theory and practice of counseling and psychotherapy (5 $5^{\text {th }}$ ed.). Pacific Grove, CA: Brooks/Cole.

2. Dickson, W. J., (1945). The Hawthorne plan of personnel counseling. American Journal of Orthopsychiatry, 15, 343-347.

3. Emerson, P., (2003). Counselor stress: Taking our own advice. Louisiana Journal of Counseling, 11, 32-42.

4. Hurrell, J. J., Jr. \& Murphy, L. R., (1992). Psychologic job stress. In Rom, W. N. (Ed.), Environmental and Occupational Medicine, (pp. 11-28).

5. $\quad$ Kelly, A. L., (2002). The 4 biggest job stressors. Shape, 22 (3), 156-168.

6. Murphy, L. R., (1988). Workplace interventions for stress reduction and prevention. InCooper, C. L. \& R. Payne (Eds.), Causes, Coping and consequences of stress at work (pp. 309-330). Chichester, West Sussex, England: John Wiley \& Sons.

7. National Institute for Occupational Safety and Health. (n.d.). Stress ...at work. Retrieved October 18, 2004, from http://www.cdc.gov/niosh/stresswk.html

8. Osipow, S. H. \& Spokane, A. R., (1987). Occupational Stress Inventory Manual: Research Version. Odessa, FL: 1987.

9. Sauter, S. L., Murphy, L. R., \& Hurrell, J. J., Jr., (1990). A national strategy for the prevention of workrelated psychological disorders. American Psychologist, 45, 1146-1158. 


\section{NOTES}

